\title{
Modelling catchment response to acid deposition: a regional dual application of the MAGIC model to soils and lakes in the Athabasca Oil Sands Region, Alberta
}

\author{
Colin J. WHITFIELD*, Julian AHERNE, B. Jack COSBY ${ }^{1)}$ and Shaun A. WATMOUGH \\ Environmental and Resource Studies, Trent University, 1600 West Bank Dr., Peterborough, ON K9J 7B8, Canada \\ ${ }^{1)}$ Department of Environmental Science, University of Virginia, Clark Hall, 291 McCormick Rd., Charlottesville, VA 22904, USA \\ *corresponding author e-mail: cwhitfield@trentu.ca
}

\begin{abstract}
The effects-based acid emissions management framework (EMF) for determining the need for emission control policies in the Athabasca Oil Sands Region, Canada is dependent on model simulations of future soil and surface water chemistry. An approach for regional application of the Model of Acidification of Groundwater in Catchments (MAGIC) was developed that addresses the differential sensitivity of forest soils and lakes. The approach used was a dual application wherein a plot-scale calibration to forest soils and a catchment-based calibration to lake chemistry were used to account for poorly understood hydrologic connections between uplands and lakes, key processes including sulphur $(S)$ and nitrogen $(N)$ retention as well as groundwater sources of base cations to the lakes. The regional application was carried out at 50 lake catchments currently monitored for response to acid deposition. Simulated forest soil chemistry (modelled at 28 catchments) exhibited small changes in base saturation under future conditions of elevated acid deposition, while in general molar BC:Al exhibited considerable change but remained well above critical chemical limits used to protect acid-sensitive forest soils. Similarly, simulations of charge balance acid neutralizing capacity $\left(A N C_{C B}\right)$ for the lakes suggested very small decreases since industrialization, and forecast projections under acid deposition double the current level suggested that only one lake will reach the critical threshold for $A N C_{C B}\left(75 \mu e q L^{-1}\right)$ specified by the EMF. There is limited potential for acidification impacts at the study sites.
\end{abstract}

Key words: acidification, Alberta, MAGIC, Oil Sands, regional, soil chemistry, surface water chemistry, Canada

\section{INTRODUCTION}

Acid deposition and its resulting impact on sensitive ecosystems has been a long-standing issue in North America (Dillon et al. 1978) and Europe (Overrein et al. 1981; Gorham 1998). Some chemical recovery has been observed in these regions owing to reductions in the emission of the acid precursor sulphur dioxide $\left(\mathrm{SO}_{2}\right)$ (Stoddard et al. 1999; Wright et al. 2005). While assessing and promoting recovery is of ongoing interest in these regions, recent efforts have also focussed on assessing the potential for impacts in newly industrialized zones (e.g., southern Asia, southern Africa, and China), where emissions of $\mathrm{SO}_{2}$ and nitrogen oxides $\left(\mathrm{NO}_{\mathrm{x}}\right)$ continue to rise and sensitive ecosystems may be at increased risk of acidification (e.g., Larssen \& Carmichael 2000; Kuylenstierna et al. 2001; Vogt et al. 2006). Developing countries are not the only locations where acidic emissions continue to rise, and despite reductions in emissions on a countrywide scale (e.g., Schöpp et al. 2003), localized regions in developed countries may also be under increased pressure from acid deposition. Dynamic models of acidification afford the opportunity to conduct prospective analysis of potential future ecosystem response to changing atmospheric deposition; this information can be used to guide emissions policies in order to avoid or limit impacts in these regions, in addition to predicting recovery times of already damaged systems.

In the Athabasca Oil Sands Region (AOSR) of northern Alberta, Canada, home to the world's second largest deposit of recoverable oil, widespread industrialization in recent years has been stimulated by rising oil prices and increasing demand for oil. As a consequence, emissions of acid precursors $\left(\mathrm{SO}_{2}, \mathrm{NO}_{\mathrm{x}}\right)$ rose during the last 30 years of the $20^{\text {th }}$ Century, making it the largest emitting region in Canada. With oil production anticipated to increase threefold over the next decade (Timilsina et al. 2005) additional increases in emissions of $\mathrm{SO}_{2}$ and $\mathrm{NO}_{\mathrm{x}}$ are probable and acid deposition is expected to rise accordingly. In recognition that much of the area surrounding the major emissions sources located near the town of Fort McMurray is acid-sensitive (Bennett et al. 2008; Carou et al. 2008), a regional emissions management framework (EMF) has been established as a means of limiting future impacts from acid deposition in the region. The EMF bases the need for emissions controls on the anticipated time at which sensitive ecosystems may pass specified thresholds of tolerable change. While these thresholds are highly debated, for management purposes critical thresholds for the region have been defined that are distinct from any other application. For forest soils, site-specific chemical thresholds used in the EMF are calculated as half the change between the estimated historical (pre- 
industrial) condition and a fixed endpoint for base saturation $(\mathrm{BS}=10 \%)$ and molar base cation $[\mathrm{BC}$ : calcium $\left(\mathrm{Ca}^{2+}\right)$, magnesium $\left(\mathrm{Mg}^{2+}\right)$, sodium $\left(\mathrm{Na}^{+}\right)$and potassium $\left(\mathrm{K}^{+}\right)$] to aluminium $\left(\mathrm{Al}^{3+}\right)$ ratio $(\mathrm{BC}: \mathrm{Al}=2)$ in soil solution. For surface waters a chemical threshold for acid neutralizing capacity (calculated from charge balance (sum of basic cations minus sum of strong acid anions): $\mathrm{ANC}_{\mathrm{CB}}$ ) of $75 \mu \mathrm{eq} \mathrm{L}^{-1}$ has been specified as the minimum acceptable level. In the event that these thresholds are predicted to be reached for more than $5 \%$ of the geographic area within 15 years, immediate emissions reductions are required. If the impact is predicted to occur within 30 years, no additional emissions will be permitted. The dynamic hydrogeochemical model MAGIC (Model of Acidification of Groundwater in Catchments: Cosby et al. 1985; Cosby et al. 2001) has been used widely to simulate historical and predict future conditions of acid-sensitive soils and surface waters in a regional setting (Sefton \& Jenkins 1998; Aherne et al. 2003; Rogora et al. 2003; Whitfield et al. 2007) and has been selected for use in supporting the EMF.

Other assessments of the acid-sensitivity of lake catchments in the AOSR have used a steady-state approach (Bennett et al. 2008) and arguably inappropriate assumptions of sulphur (S) behaviour, or have been limited to few sites (Whitfield et al. 2010a, this issue). Ultimately, the EMF requires that MAGIC be applied regionally in order to represent the potential chemical change across a much wider geographic area. In this study, the objective was to develop an approach for applying MAGIC to a large number of lake catchments. There are many challenges to applying MAGIC in this environment, and a method that accounts for the dominant processes that determine ecosystem response to acid deposition: input of mineral rich groundwater to the lakes, retention of $\mathrm{S}$ and $\mathrm{N}$ in the terrestrial catchments, and weathering sources of $\mathrm{SO}_{4}{ }^{2-}$ and $\mathrm{Cl}^{-}$must be incorporated. Furthermore, the topography across the region makes delineation of catchment boundaries difficult, hydrology is strongly influenced by catchment landscape structure, and chemical and physical data describing the catchments are very limited, all of which stand to complicate the model application. In order to address these challenges, a new approach to regional MAGIC application that incorporates dual calibrations to both forest soil and lake chemistry was developed for use in the AOSR. Owing to groundwater influences on lake chemistry in these catchments, a plot-scale application is necessary for assessing the response of forest soils to acidic deposition in this region. MAGIC was calibrated and applied to 50 lake catchments and to forest soil plots located in 28 of these catchments; the catchments are distributed widely across the region, represent a range of acid-sensitivity and span a gradient of acid deposition. The potential for chemical change in these systems with respect to the thresholds defined by the EMF was assessed.

\section{METHODS}

\subsection{Climate and study sites}

The AOSR comprises the region surrounding the town of Fort McMurray, Alberta $\left(56.7^{\circ} \mathrm{N}, 123.4^{\circ} \mathrm{W}\right)$ that is largely underlain by oil sand deposits. The study region lies mostly in the Boreal Plains ecozone, but the northernmost areas are located in the Taiga Plains or Taiga Shield ecozones. The climate of the region is continental boreal, with average daily temperatures ranging from $-18.8{ }^{\circ} \mathrm{C}$ (January) to $16.8{ }^{\circ} \mathrm{C}$ (July) in Fort McMurray (Environment Canada 2009), and annual average precipitation of approximately $530 \mathrm{~mm}$ (Mesinger et al. 2006). Dystrophic lakes are a common feature of the region, and muskeg peatlands cover up to $50 \%$ of the landscape (D.H. Vitt, pers. comm.), with poor fens dominating in many catchments, and bog areas also common. Fifty lake catchments distributed across an area of approximately $120,000 \mathrm{~km}^{2}$ and grouped into six sub-regions were included in this analysis (Fig. 1). The lakes were chosen by Alberta Environment to be included in their acid-sensitive lakes monitoring program; they are remote and are accessible only via float plane or helicopter. Catchments in the AOSR have a wide range in physical characteristics and are subject to variable hydrologic influences (Bennett et al. 2008). Four of the sub-regions (Birch Mountains: BM; Northeast of Fort McMurray: NE; Stony Mountains: SM; West of Fort McMurray: WF) are located immediately surrounding Fort McMurray and are close $(<200 \mathrm{~km})$ to the core of industrial activity and principle emission sources for the region, while two sub-regions (Caribou Mountains: CM; Shield: S), are located further afield, at the northernmost limits of the study area (Fig. 1), and as such will be under less pressure from acidic deposition. Lake catchments in the BM sub-region are large and predominantly forested. These lakes tend to be deeper and consequently have longer retention times, despite having high catchment discharge (Tab. 1). In the NE sub-region catchment relief is limited, extensive fen complexes are a common landscape feature, and average lake retention times are short (Tab. 1). Catchments in the WF and SM sub-regions tend to be smaller than in the other sub-regions, and have the lowest runoff, with WF lakes generally having the highest dissolved organic carbon (DOC) concentrations. The CM sub-region is located on a large peat plateau in north-central Alberta and has the greatest elevation above sea-level $(1000 \mathrm{~m})$; peaty soils underlain by permafrost are common in these catchments. Average catchment size in the $\mathrm{S}$ sub-region is large and these catchments feature coniferous forests on mineral soils, sporadic areas of exposed granitic bedrock, and relatively small areas of organic soil (Tab. 1). Mineral soils across the region are generally sandy, dominated by poorly weatherable minerals (e.g., quartz) and therefore acid-sensitive. 


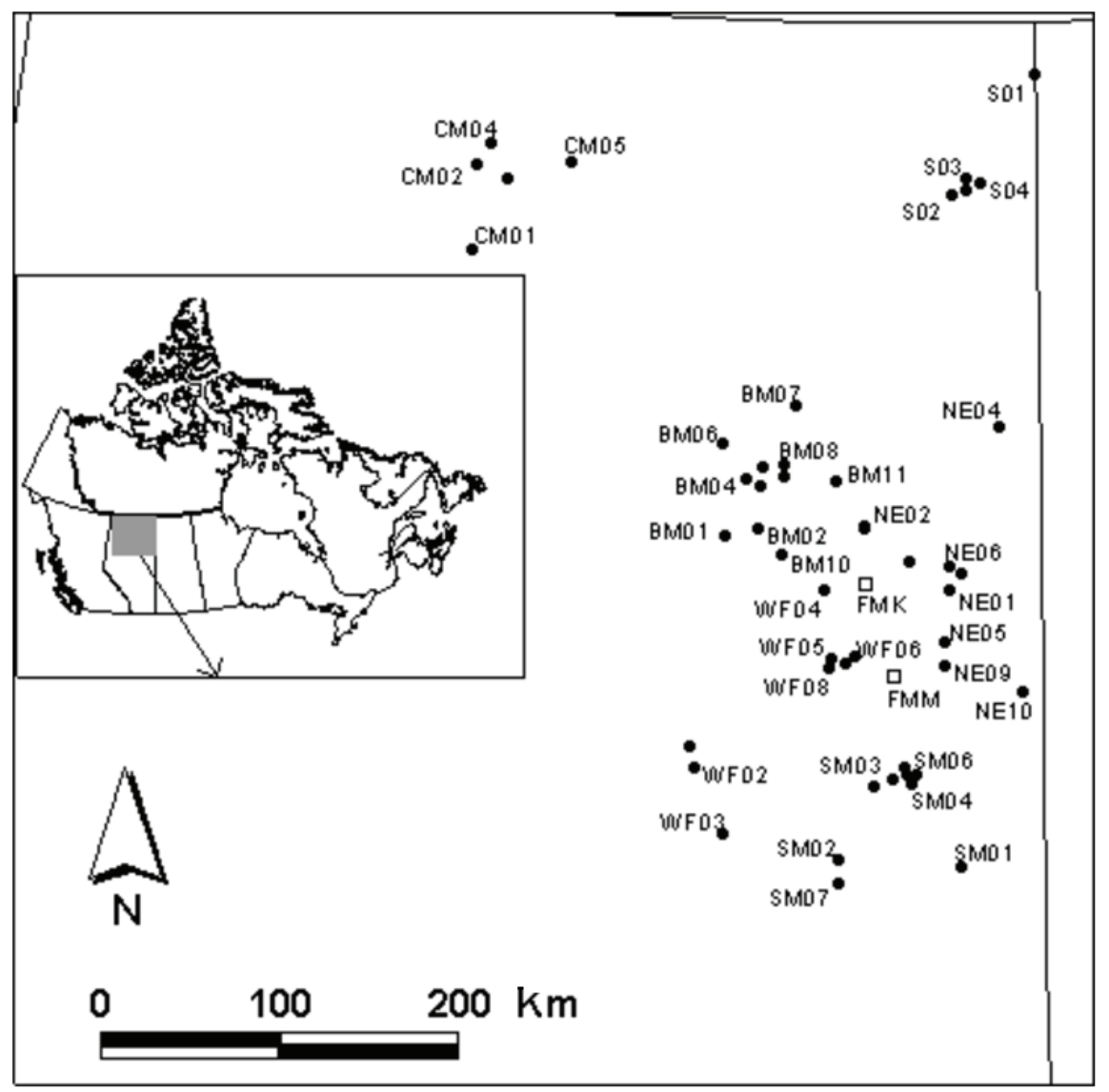

Fig. 1. Map of the study area, including 50 lake catchments (filled circles, some of which overlap), and the towns (open squares) of Fort McMurray (FMM) and Fort McKay (FMK) between which the major emissions sources of the region are located. The location of the study area in Canada is shown in grey on the inset map.

Tab. 1. Summary of average lake catchment chemical and physical properties, and atmospheric deposition by sub-region, with minimum and maximum (catchment area) or standard deviations (all other parameters) in parentheses.

\begin{tabular}{|c|c|c|c|c|c|c|c|}
\hline & Units & $\mathrm{BM}$ & $\mathrm{NE}$ & SM & WF & $\mathrm{CM}$ & $\mathrm{S}$ \\
\hline Number of lakes & & 11 & 11 & 10 & 8 & 5 & 5 \\
\hline Catchment area & $\mathrm{km}^{2}$ & $37.4(0.6,165)$ & $17(0.8,77.2)$ & $10.4(3.7,18.2)$ & $12.8(1.6,51.6)$ & $27.9(2.8,46.8)$ & $57.3(5.1,112)$ \\
\hline Lake relative area & $\%$ & $12(8)$ & $12(10)$ & $16(9)$ & $10(10)$ & $12(7)$ & $6.6(8.0)$ \\
\hline Peatland relative area & $\%$ & $30(12)$ & $43(18)$ & $42(17)$ & $28(10)$ & $31(23)$ & $23(4)$ \\
\hline Retention time & $\mathrm{yr}$ & $4.3(10.7)$ & $0.8(0.8)$ & $1.8(1.4)$ & $2.4(1.5)$ & $1.4(0.4)$ & $2.1(1.8)$ \\
\hline Catchment discharge & $\mathrm{my}^{-1}$ & $0.33(0.24)$ & $0.18(0.12)$ & $0.13(0.03)$ & $0.09(0.01)$ & $0.28(0.08)$ & $0.14(0.07)$ \\
\hline Precipitation & $\mathrm{m} \mathrm{y}^{-1}$ & $0.47(0.02)$ & $0.53(0.01)$ & $0.55(0.01)$ & $0.56(0.02)$ & $0.43(0.02)$ & $0.40(0.00)$ \\
\hline Calcium & $\mu e q L^{-1}$ & 245 (159) & $458(357)$ & $104(70)$ & 439 (207) & $268(99)$ & $287(75)$ \\
\hline Magnesium & $\mu e q L^{-1}$ & $135(96)$ & $233(190)$ & $63(45)$ & $224(136)$ & $109(37)$ & $150(30)$ \\
\hline Sodium & $\mu$ eq $\mathrm{L}^{-1}$ & $113(101)$ & $125(111)$ & $41(17)$ & $92(83)$ & $35(11)$ & $77(10)$ \\
\hline Potassium & $\mu$ eq $\mathrm{L}^{-1}$ & $14(7)$ & $7(6)$ & $15(13)$ & $19(7)$ & $7(4)$ & $16(4)$ \\
\hline Ammonium & $\mu$ eq L $\mathrm{L}^{-1}$ & $5.2(0.4)$ & $5.4(0.6)$ & $6.7(0.6)$ & $6.3(0.7)$ & $4.7(0.3)$ & $3.5(0.3)$ \\
\hline Sulphate & $\mu \mathrm{eq} \mathrm{L}^{-1}$ & $108(88)$ & $21(21)$ & $21(10)$ & $49(66)$ & $43(18)$ & $20(8)$ \\
\hline Chloride & $\mu \mathrm{eq} \mathrm{L} \mathrm{L}^{-1}$ & $5.1(1.1)$ & $6.9(3.4)$ & $7.4(4.6)$ & $9.7(3.7)$ & $6.5(4.7)$ & $42(17)$ \\
\hline Nitrate & $\mu e q L^{-1}$ & $0.6(0.8)$ & $0.2(0.2)$ & $0.2(0.2)$ & $0.6(1.5)$ & $0.4(0.2)$ & $0.08(0.04)$ \\
\hline Dissolved organic carbon & $\operatorname{mg~L}^{-1}$ & $21(10)$ & $26(8)$ & $18(4)$ & $34(10)$ & $21(4)$ & $17(4)$ \\
\hline $\mathrm{pH}$ & & $5.26(0.94)$ & $6.00(0.99)$ & $5.30(0.90)$ & $5.92(0.82)$ & $6.67(0.31)$ & $7.08(0.15)$ \\
\hline Sulphate deposition & meq $\mathrm{m}^{-2} \mathrm{y}^{-1}$ & $21.3(1.8)$ & $24.0(2.6)$ & $23.3(1.5)$ & $25.1(2.1)$ & $10.3(0.6)$ & $8.5(0.4)$ \\
\hline Nitrogen deposition & meq $\mathrm{m}^{-2} \mathrm{y}^{-1}$ & $10.4(0.9)$ & $10.8(1.2)$ & $13.3(1.1)$ & $12.7(1.3)$ & $9.4(0.6)$ & $7.0(0.7)$ \\
\hline Base cation deposition & meq $\mathrm{m}^{-2} \mathrm{y}^{-1}$ & $15.2(1.1)$ & $16.9(0.8)$ & $18.8(2.4)$ & $17.7(0.8)$ & $10.1(0.3)$ & $11.7(0.7)$ \\
\hline
\end{tabular}


In some of the sub-regions mineral soils of a less acid-sensitive nature occur, and base-rich geologic parent material (Devito et al. 2000) underlying the aeolian or glacialfluvial surficial deposits is common in the wider region. Upland forest soils were sampled at 28 of the study catchments.

\subsection{The Model}

MAGIC (Cosby et al. 1985) is a process-oriented lumped parameter model of intermediate complexity, and can be used to simulate average annual or monthly soil solution and surface water concentrations for inorganic nitrogen [N: ammonium $\left(\mathrm{NH}_{4}^{+}\right)$and nitrate $\left(\mathrm{NO}_{3}{ }^{-}\right)$], chloride $\left(\mathrm{Cl}^{-}\right)$, sulphate $\left(\mathrm{SO}_{4}{ }^{2-}\right), \mathrm{Ca}^{2+}, \mathrm{Mg}^{2+}, \mathrm{Na}^{+}, \mathrm{K}^{+}$, $\mathrm{Al}^{3+}$ and $\mathrm{pH}$, as well as exchangeable soil fractions of $\mathrm{Ca}^{2+}, \mathrm{Mg}^{2+}, \mathrm{Na}^{+}$and $\mathrm{K}^{+}$. The structure of the model has been described in detail by Cosby et al. (2001) and model version 7.77ext was used in the current study. The model can be used to represent uniform mineral soil, wetland (organic soil), and surface water compartments (lake or stream) using aggregated data. Equilibrium equations including aluminium reactions for surface and soil water, cation exchange reactions, buffering of soil solution $\mathrm{pH}$ by weak organic and inorganic acids, and inorganic carbon equations that describe the chemical change that occurs as soil water reaches the surface and is exposed to the atmosphere are used to describe short-term processes. Long-term input-output processes including mineral weathering, anion retention by soils, and biologically mediated uptake of cations and anions control the catchment mass balance; rates of change for each ion in soil water and surface water are calculated through mass balance equations.

\subsection{Data sources}

\subsubsection{Lakes}

Lake water collection at the 50 catchments started in either 2001 (39 lakes) or 2002 (11 lakes) and lake chemistry data through to 2007 were included in this analysis. Samples were collected annually by Alberta Environment during the last week of August or first week of September. Lake water was collected in HDPE bottles from a depth of $20 \mathrm{~cm}$ at mid-lake and stored on ice for transport to the University of Alberta, usually within 48 hours of collection. Samples were analyzed for Gran alkalinity, $\mathrm{NH}_{4}{ }^{+}, \mathrm{NO}_{3}^{-}$, total $\mathrm{N}, \mathrm{DOC}$, dissolved inorganic carbon (DIC), $\mathrm{Cl}^{-}, \mathrm{SO}_{4}{ }^{2-}, \mathrm{Na}^{+}, \mathrm{K}^{+}$, $\mathrm{Ca}^{2+}$, and $\mathrm{Mg}^{2+}$ in the laboratory, while electrical conductivity and $\mathrm{pH}$ were measured during site visits. Data quality was evaluated using charge balance, with $\pm 25 \%$ set as the criterion for acceptance; samples excluded from the analysis $(n=9)$ generally had an error of $40 \%$ or more, while the majority of samples $(92 \%)$ had a charge balance error less than $20 \%$. Lake chemistry data show considerable interannual variability and no temporal trend. As such, average (2001/2002-2007) annual ion concentrations and $\mathrm{pH}$ were used as target values for model calibration. Data detailing physical characteristics of the lakes and catchments were provided by Alberta Environment.

\subsubsection{Soils}

Mineral soils were sampled at all catchments where access was possible during site visits $(\mathrm{n}=28)$; soils were collected from a single pit in the years 2005 or 2006. Protocols for soil sampling and analysis have been previously described (Whitfield et al. 2010a, this issue; Whitfield et al. 2009). Briefly, a bulk sample of the litter, fibric, humic (LFH) layer and mineral soil horizons (A, B) was collected from each soil pit, and horizon depths were recorded. Soils were analyzed for loss on ignition (LOI), exchangeable base cations (eBC), cation exchange capacity (CEC), and $\mathrm{pH}$. Bulk density (BD) was calculated from the dry mass and sample volume (LFH), or from LOI (mineral soils) using a pedotransfer function (De Vos et al. 2005). Soils were analyzed for particle size (Horiba ${ }^{\mathrm{TM}}$ Partica LA950) and mineralogy (Siemens ${ }^{\mathrm{TM}}$ (Bruker) D5000 Bragg-Brentano diffractometer). Where possible organic soil samples were collected from the actrotelm of peatlands $(n=20)$; this fibric peat was analyzed for $\mathrm{pH}, \mathrm{eBC}$ and $\mathrm{CEC}$.

\subsubsection{Atmospheric deposition}

Deposition of $\mathrm{NH}_{4}^{+}, \mathrm{NO}_{3}{ }^{-}, \mathrm{SO}_{4}{ }^{2-}, \mathrm{Ca}^{2+}$, and $\mathrm{Mg}^{2+}$ was measured during the 2005-2008 period at select sites across the BM, NE, WF and SM sub-regions and used to create a deposition field for these elements at a resolution of $4 \mathrm{~km}$ by $4 \mathrm{~km}$ (see Whitfield et al. 2009). For the other elements and sub-regions deposition data were more limited, and regional deposition maps were used to estimate deposition. Total deposition for $\mathrm{NH}_{4}{ }^{+}$, $\mathrm{NO}_{3}^{-}, \mathrm{SO}_{4}{ }^{2-}, \mathrm{Ca}^{2+}$, and $\mathrm{Mg}^{2+}$ at the northern sub-regions $(\mathrm{CM}, \mathrm{S})$ was estimated from regional maps of wet and dry deposition for the period 1994-1998 at a resolution of $35 \mathrm{~km} \times 35 \mathrm{~km}$ (Vet \& Shaw 2004) and scaled according to the deposition scenarios (described below) to estimate total deposition for the calibration year (2005). Deposition of $\mathrm{Na}^{+}, \mathrm{K}^{+}$, and $\mathrm{Cl}^{-}$makes up a minor component of deposition inputs, and was assumed to show negligible temporal change; total deposition for all 50 sites was estimated from regional maps of wet and dry deposition for the period 19941998 at a resolution of $35 \mathrm{~km} \times 35 \mathrm{~km}$ (Vet \& Shaw 2004).

A single hindcast (1900-2005) and two forecast (base case, double acid) deposition scenarios (20062035) were established to reflect changes in atmospheric deposition over the period of model simulation (Whitfield et al. 2010a, this issue). In brief, S deposition increased from the 1960s through the 1990s, while increases in N deposition took place largely after 1990. Base cations $\left(\mathrm{Ca}^{2+}\right.$ and $\left.\mathrm{Mg}^{2+}\right)$ were estimated to have increased approximately two-fold over background lev- 
els. Under the 'base case' forecast scenario, all emissions remain at 2005 levels for the duration of the forecast, while for the 'double acid' scenario, $\mathrm{S}$ and $\mathrm{N}$ deposition double linearly through 2020 following rises in production level (Timilsina et al. 2005), and remain constant thereafter. For the northern sites, acid deposition was much lower than in the southern sub-regions, which strongly suggests that atmospheric deposition at these remote locations is composed of contributions from different source regions (i.e. the effect of industries in the AOSR on deposition is small). The deposition scenarios for these sites were modified to have a more gradual rise in acid emissions, such that historical increases in deposition of $\mathrm{S}$ and $\mathrm{N}$ above 2005 levels reflect less (30\%) of the increase estimated for the southern sites.

\subsection{Weathering rates}

Mineral soil weathering rates were estimated using the PROFILE model (Warfinge \& Sverdrup 1992). PROFILE is a steady-state soil chemistry model with a weathering rate sub-model. The weathering rate submodel calculates weathering rates (for each base cation) explicitly using independent soil properties. Climate data, soil physicochemical properties and detailed soil mineralogy are inputs to the model; site-specific data were used for as many model parameters as possible owing to model sensitivity to some inputs (e.g., bulk density, surface area, mineralogy) (Hodson et al. 1996). Sand, silt and clay contents determined through particle size analysis were used to calculate the surface area according to Hodson et al. (1998). Weathering rates were estimated for a standardized depth of $0.6 \mathrm{~m}$ (approximate depth of the rooting zone). Average annual soil moisture $\left(0.18 \mathrm{~m}^{3} \mathrm{~m}^{-3}\right)$ and temperature $\left(3.6{ }^{\circ} \mathrm{C}\right)$ were measured at (and comparable between) two sites (Whitfield et al. 2010a, this issue), and used as default values for the entire region.

\subsection{Model calibration}

Previous model applications for the region describe in detail the approach used to simulate response to atmospheric deposition at the individual lake catchment (Whitfield et al. 2010a, this issue) and forest plot scales (Whitfield et al. 2009). Here we present an approach for model application that can be used to calibrate multiple catchments across the region. The regional application of MAGIC requires the use of an iterative automated optimization procedure (MAGICOPT). This optimization procedure is 'fuzzy' as values for parameters with uncertainty are randomly selected within an uncertainty band (range around the average value) during calibration. The iterative optimization procedure uses numerical techniques to select the parameter values until simulated values that minimize the sum of squared errors between simulated and observed values are reached. For the AOSR catchments it is not possible to use a typical optimization procedure that calibrates to lake and soil chemistry simultaneously owing to the frequent occurrence of large base cation sources (groundwater) in the catchments. Instead, an application procedure that independently calibrates to forest soils (at 28 sites only) and lakes (50 study catchments) is used. This encompasses a plot-scale regional application to catchment mineral soils, and a two phase calibration to lake chemistry (Fig. 2). For both approaches 2005 was used as the calibration year, as this coincided with the mid-point of lake chemistry observations and the period of soil sampling.

\subsubsection{Soils}

A plot-scale application of MAGIC (see also Whitfield et al. 2009) was conducted at all catchments where mineral soil data were collected. In general the study catchments are large, and sampling at one soil pit is insufficient to represent mineral soils across the whole catchment. Rather the plot-scale application can be used as an example of soil response in the catchment that would otherwise be impossible to represent under a traditional catchment-based application. MAGIC was calibrated to an amalgamated (i.e. depth and density weighted) soil layer constructed from observed soil data from the rooting zone (depth of $0.6 \mathrm{~m}$ ), with BS and soil $\mathrm{pH}$ used as target values (Tab. 2). As a simplification of the regional modelling approach, the forest stands in these catchments were assumed to have reached a climax state and to be free of harvesting; thus no net elemental uptake was catalogued during model parameterization and complete $\mathrm{N}$ retention in soils was assumed. For each plot, weathering rates were fixed according to PROFILE generated estimates (Tab. 2), and multiple (n $=10$ ) calibrations were carried out using the fuzzy fixed parameter approach with percolation water loss, depth, bulk density, CEC, aluminium solubility coefficient $(\mathrm{KAl})$ varied randomly within specified uncertainty bands $( \pm 10 \%$ or \pm 0.5 for $\mathrm{KAl})$. Because $\mathrm{KAl}$ is unknown for these sandy soils while the log of selectivity coefficients for aluminium-calcium and aluminiummagnesium are expected to range from $1-3$, the KAl value used as a fuzzy fixed parameter was manually calibrated to achieve selectivity coefficients in this range. The aluminium solubility coefficient was initially set at 9, and modelled selectivity coefficients were evaluated following the optimization; KAl was adjusted prior to the next optimization and the process iterated (Fig. 2). It is expected that using this constraint to guide the model to simulate acceptable conditions for an additional soil target (selectivity coefficients) yields a more realistic model simulation. A maximum DOC concentration of $200 \mu \mathrm{mol} \mathrm{L}{ }^{-1}$ was specified, and subsequently adjusted through the automated procedure in order to match simulated and observed soil $\mathrm{pH}$ values. Default values for the region (Whitfield et al. 2009) were used where site-specific data were not available (Tab. 2). Narrow windows for acceptance of exchangeable fraction $( \pm 0.25 \%)$ and soil $\mathrm{pH}( \pm 0.75)$ were imposed to ensure agreement between simulated and observed values. 
Plot-scale application

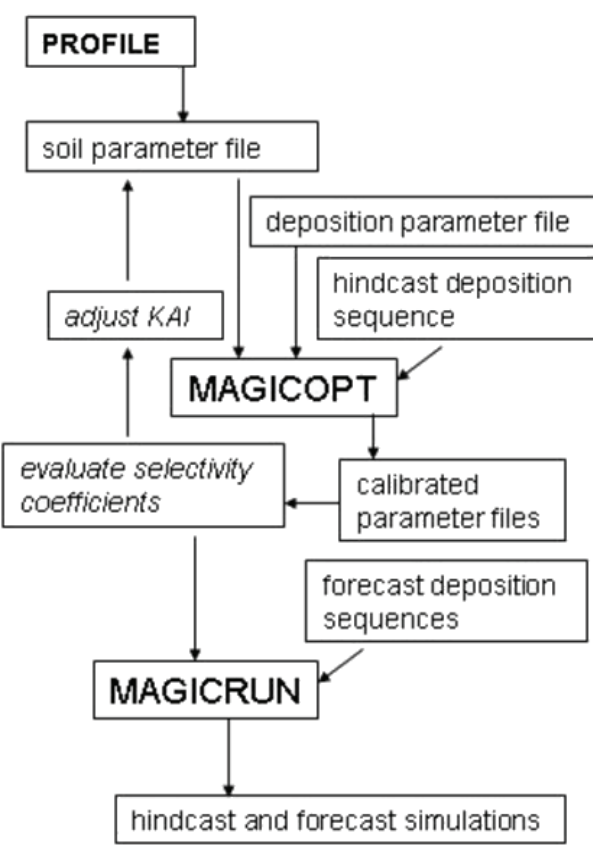

Lake application

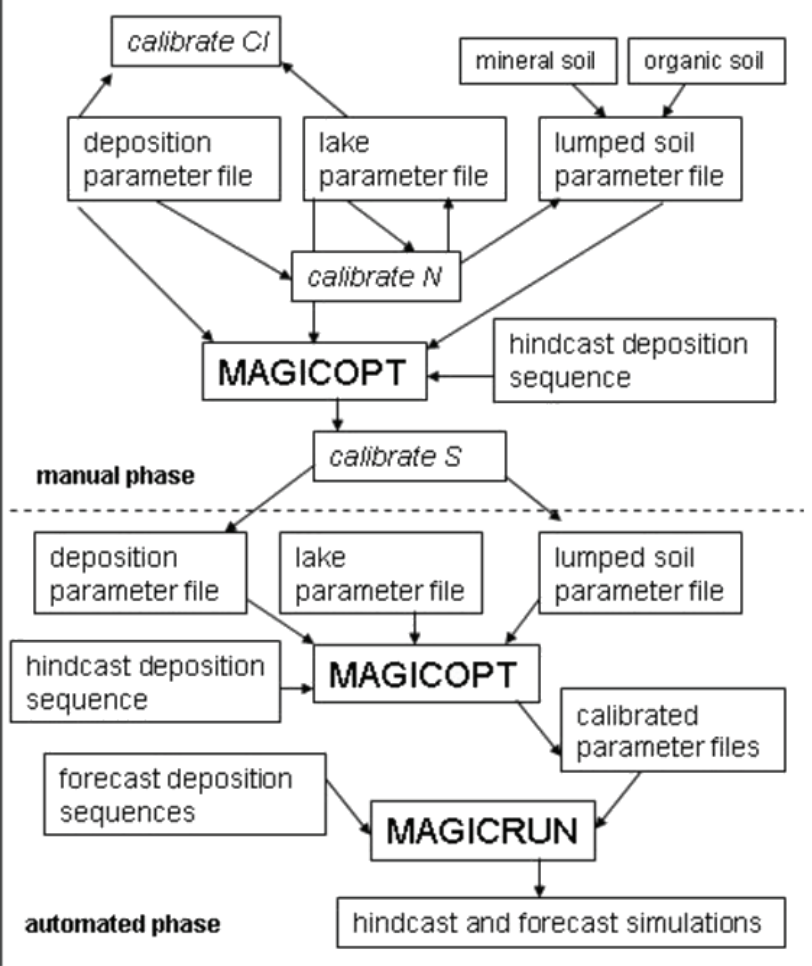

Fig. 2. Schematic overview of the regional approach to MAGIC application.

Tab. 2. Input parameters used for the soil plot-scale MAGIC application. *Default parameters for temperature $\left(3.6^{\circ} \mathrm{C}\right), \mathrm{SO}_{4}{ }^{2-}$ adsorption half saturation $\left(500 \mu \mathrm{eq} \mathrm{L}^{-1}\right)$ and $\mathrm{SO}_{4}{ }^{2-}$ adsorption maximum capacity $\left(7.5 \mathrm{meq} \mathrm{kg}^{-1}\right)$ were used for all sites; ${ }^{\text {a)}: ~ M A G I C ~ c a l i b r a t e d ~ p a r a m e t e r ; ~}{ }^{\text {b) }}$ : PROFILE modelled parameter

\begin{tabular}{|c|c|c|c|c|c|c|c|c|}
\hline Site & $\begin{array}{l}\text { Runoff } \\
(\mathrm{m})\end{array}$ & $\mathrm{pH}$ & $\begin{array}{l}\text { Bulk density } \\
\left(\mathrm{kg} \mathrm{m}^{-3}\right)\end{array}$ & $\begin{array}{c}\text { Base saturation } \\
\%\end{array}$ & $\begin{array}{c}\mathrm{CEC} \\
\left(\text { meq } \mathrm{kg}^{-1}\right)\end{array}$ & $\begin{array}{c}\text { Porosity } \\
\text { (\%) }\end{array}$ & $\begin{array}{l}\text { Aluminium solubil. }{ }^{\text {a) }} \\
(\log )\end{array}$ & $\begin{array}{l}\text { Weathering rate }{ }^{\mathrm{b})} \\
\left(\text { meq } \mathrm{m}^{-2} \mathrm{y}^{-1}\right)\end{array}$ \\
\hline BM01 & 0.117 & 4.76 & 1367 & 27.6 & 80 & 43 & 8.00 & 3.5 \\
\hline BM02 & 0.117 & 5.16 & 1393 & 70.2 & 231 & 42 & 10.00 & 62.8 \\
\hline BM03 & 0.112 & 5.85 & 1397 & 69.3 & 105 & 35 & 9.75 & 26.0 \\
\hline BM05 & 0.120 & 4.90 & 1232 & 38.2 & 258 & 27 & 9.75 & 53.6 \\
\hline BM07 & 0.113 & 4.17 & 1087 & 8.4 & 239 & 59 & 8.50 & 19.7 \\
\hline BM08 & 0.119 & 5.10 & 1036 & 65.2 & 268 & 57 & 8.25 & 35.4 \\
\hline BM10 & 0.116 & 5.91 & 1479 & 82.4 & 145 & 13 & 9.50 & 41.7 \\
\hline BM11 & 0.108 & 5.39 & 1642 & 16.6 & 31 & 24 & 10.25 & 5.6 \\
\hline CM01 & 0.107 & 5.87 & 1146 & 11.9 & 2326 & 40 & 10.50 & 22.4 \\
\hline NE02 & 0.123 & 5.24 & 1566 & 42.4 & 49 & 8 & 8.75 & 15.1 \\
\hline NE04 & 0.124 & 4.50 & 1689 & 20.2 & 21 & 21 & 7.75 & 1.7 \\
\hline NE07 & 0.124 & 4.43 & 1692 & 40.2 & 71 & 20 & 7.75 & 27.8 \\
\hline NE08 & 0.125 & 5.46 & 1100 & 67.4 & 70 & 49 & 8.75 & 7.5 \\
\hline NE10 & 0.117 & 5.20 & 1638 & 52.9 & 34 & 32 & 8.25 & 7.1 \\
\hline NE11 & 0.124 & 5.08 & 1517 & 37.2 & 51 & 37 & 8.50 & 3.6 \\
\hline S01 & 0.094 & 5.13 & 1411 & 18.8 & 50 & 47 & 9.75 & 24.7 \\
\hline $\mathrm{S} 03$ & 0.094 & 5.04 & 1528 & 36.9 & 45 & 29 & 8.25 & 20.0 \\
\hline S04 & 0.094 & 4.67 & 1391 & 17.0 & 59 & 35 & 8.00 & 3.2 \\
\hline SM01 & 0.114 & 5.59 & 1666 & 50.0 & 24 & 37 & 9.50 & 6.7 \\
\hline SM02 & 0.115 & 4.87 & 1499 & 46.6 & 119 & 37 & 9.75 & 44.7 \\
\hline SM03 & 0.127 & 4.66 & 1517 & 37.5 & 104 & 37 & 8.00 & 28.0 \\
\hline SM05 & 0.119 & 5.55 & 1595 & 44.2 & 65 & 26 & 9.50 & 18.8 \\
\hline SM07 & 0.111 & 5.26 & 1673 & 45.4 & 54 & 22 & 8.75 & 14.7 \\
\hline SM08 & 0.111 & 4.39 & 1371 & 32.3 & 176 & 36 & 8.25 & 28.0 \\
\hline SM09 & 0.127 & 4.60 & 1433 & 3.7 & 167 & 40 & 9.75 & 29.2 \\
\hline WF01 & 0.098 & 5.69 & 1542 & 66.3 & 77 & 19 & 9.50 & 24.0 \\
\hline WF07 & 0.158 & 5.63 & 1528 & 66.2 & 105 & 20 & 9.00 & 24.1 \\
\hline WF08 & 0.147 & 4.77 & 1473 & 41.2 & 99 & 38 & 8.00 & 11.7 \\
\hline
\end{tabular}




\subsubsection{Lakes}

Individual parameter files were prepared for each catchment using site-specific data, with each catchment configured as one soil and one lake compartment, and calibrated using an annual time step. Estimates of discharge from the catchments were available from two sources, isotope mass balance (J.J. Gibson, pers. comm.) and regional interpolation at a $35 \mathrm{~km} \times 35 \mathrm{~km}$ resolution (data provided by M. Posch, ICP Co-ordination Centre for Effects); the higher of the two estimates was used. Soils within each catchment were represented using one lumped compartment that combines both mineral and organic soil data weighted according to spatial coverage and soil depth. For sites where no mineral soil data were available $(\mathrm{n}=22)$, average mineral soil data for the sub-region were used as inputs. Similarly, as relatively few organic soil samples were collected, organic soil data for each sub-region was averaged and used for each catchment in that region. The physical aspects of the organic soils were described according to Whitfield et al. (2010a, this issue), and default values were used for a number of soil and lake parameters (Tab. 3). Because the lake calibration involves a relatively unconstrained optimization of base cation weathering in the soil compartment, the soil data used have little influence on predictions of base cation concentrations in the lake, but nevertheless parameterization of the soil compartment is a necessary step in this calibration.

Tab. 3. Default input parameters for the soil and surface water compartments used for the lake calibrations.

\begin{tabular}{lccc}
\hline Parameter & Units & Soil & Lake \\
\hline Dissolved organic carbon & $\mu \mathrm{mol} \mathrm{L}^{-1}$ & 200 & - \\
$\mathrm{SO}_{4}{ }^{2-}$ adsorption half saturation & $\mu \mathrm{eq} \mathrm{L}^{-1}$ & 100 & - \\
$\mathrm{SO}_{4}{ }^{2-}$ adsorption maximum capacity & $\mathrm{meq} \mathrm{kg}^{-1}$ & 0.1 & - \\
Temperature & ${ }^{\circ} \mathrm{C}$ & 3.6 & 3.6 \\
Aluminium solubility constant & $\log$ & 9.0 & 7.5 \\
$\mathrm{CO}_{2}$ partial pressure & $\mathrm{atm}(\times 100)$ & 0.40 & 0.037 \\
\hline
\end{tabular}

Application of MAGIC at the lake level was carried out for all 50 catchments using a two phase calibration (Fig. 2). Catchments in the study area can act as net sinks for N, S and $\mathrm{Cl}^{-}$(Whitfield 2009), but these patterns do not hold across the wider group of study lakes, particularly for S (Fig. 3) as some catchments are a net source of $\mathrm{SO}_{4}{ }^{2-}$. Furthermore, because catchment boundaries and areas of organic and mineral soils are not well defined, specifying elemental sources or sinks within the soil compartments is not conducive to a regional calibration. Instead, the first (manual) phase of model application employed a number of offline calibration techniques in order to match simulated and observed lake $\mathrm{SO}_{4}{ }^{2-}, \mathrm{NO}_{3}{ }^{-}, \mathrm{NH}_{4}{ }^{+}$, and $\mathrm{Cl}^{-}$concentrations (e.g., Aherne et al. 2008). These calculations were used in the site-specific parameter files input to the automated optimization program (MAGICOPT). The second (automated) phase calibrated lake $\mathrm{Ca}^{2+}, \mathrm{Mg}^{2+}$, $\mathrm{Na}^{+}$and $\mathrm{K}^{+}$concentrations, lake $\mathrm{pH}$ (and soil exchangeable fractions of $\mathrm{Ca}^{2+}, \mathrm{Mg}^{2+}, \mathrm{Na}^{+}$and $\mathrm{K}^{+}$). Weathering rates and initial exchangeable base cation fractions were adjusted in order to match simulated to observed (target) values; tolerance levels around the target values of 3 $\mu$ eq $\mathrm{L}^{-1}$ for lake $\mathrm{Ca}^{2+}$ and $\mathrm{Mg}^{2+}$ concentrations, $2 \mu \mathrm{eq}$ $\mathrm{L}^{-1}$ for lake $\mathrm{Na}^{+}$and $\mathrm{K}^{+}$concentrations, and $0.2 \%$ for soil exchangeable fractions were specified.

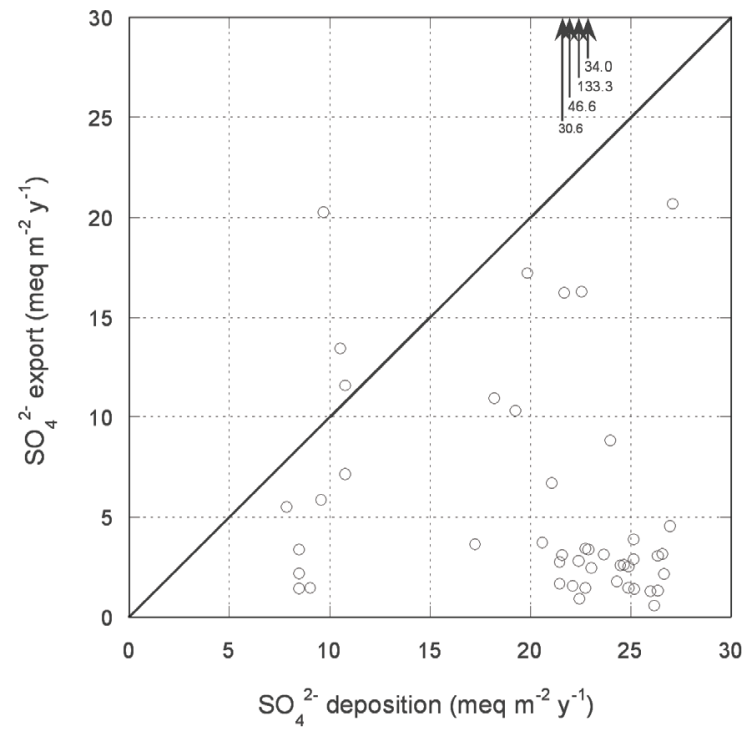

Fig. 3. Comparison of modelled sulphate $\left(\mathrm{SO}_{4}{ }^{2-}\right)$ deposition and average annual catchment export of $\mathrm{SO}_{4}{ }^{2-}$ at the 50 study lakes, with 1:1 line shown in black.

\subsubsection{Phase one}

The behaviour of $\mathrm{Cl}^{-}$is often assumed conservative in model applications (e.g. Whitfield et al. 2007), however in the AOSR there is evidence that $\mathrm{Cl}^{-}$is retained in peatlands (Whitfield 2009) and another site-specific MAGIC application included a $\mathrm{Cl}^{-}$sink in the wetland compartment (Whitfield et al. 2010a, this issue). Catchment input and export of $\mathrm{Cl}^{-}$across the 50 study lakes suggests small $\left(<1\right.$ meq $\left.\mathrm{m}^{-2} \mathrm{y}^{-1}\right)$ imbalances at the majority of the catchments, with a bias towards retention (29 of 50). Ten catchments have a larger imbalance $\left(>1 \mathrm{meq} \mathrm{m}^{-2} \mathrm{y}^{-1}\right)$ that suggests a possible weathering source of $\mathrm{Cl}^{-}$. Small errors between inputs and outputs of $\mathrm{Cl}^{-}$may result from uncertainty in catchment areas, or in deposition estimates, although modelled $\mathrm{Cl}^{-}$deposition is low and relatively uniform across the region. The hindcast deposition sequence for $\mathrm{Cl}^{-}$was constant, which allowed deposition fluxes to be calibrated such that total deposition to the catchment was equal to the runoff flux.

The deposition flux of $\mathrm{NH}_{4}{ }^{+}$and $\mathrm{NO}_{3}{ }^{-}$to the lake surface at most of the catchments was greater than their export from the lake. As such, retention in the lake was calculated as the difference between deposition inputs 
and loss via runoff, assuming inorganic $\mathrm{N}$ was retained (100\% uptake) in the terrestrial (soil) compartment. As organic $\mathrm{N}$ is not an acidifying agent, it is not considered in the model; however fluxes of organic $\mathrm{N}$ from these catchments are not negligible, and specifying complete inorganic $\mathrm{N}$ retention in the terrestrial environment should not imply that (total) $\mathrm{N}$ is quantitatively retained. For catchments where export of $\mathrm{NH}_{4}^{+}$and/or $\mathrm{NO}_{3}{ }^{-}$ exceeded direct deposition to the lake, $\mathrm{N}$ retention in the soil compartment was lowered by an amount equal to the deficit between deposition to and export from the lake. It was assumed that $\mathrm{N}$ retention in the catchment as a proportion of deposition is constant over time.

The capacity for $\mathrm{SO}_{4}{ }^{2-}$ retention in mineral soils in the AOSR has been shown to be limited (Whitfield 2009) and $\mathrm{SO}_{4}{ }^{2-}$ was assumed to behave relatively conservatively and low default values were specified for $\mathrm{SO}_{4}{ }^{2-}$ adsorption maximum capacity and half saturation (Tab. 3). Furthermore, while retention of $\mathrm{SO}_{4}{ }^{2-}$ in the peatlands in the study catchments is likely to occur, some catchments exhibit clear sources; $\mathrm{SO}_{4}{ }^{2-}$ deposition to all catchments was adjusted based on their individual behaviour. Following calibration of $\mathrm{N}^{-}$and $\mathrm{Cl}^{-}$, site-specific input parameter files were input to MAGICOPT, and a (preliminary) run in the absence of any constraints (no optimization, no targets) was completed in order to simulate the theoretical concentration of $\mathrm{SO}_{4}{ }^{2-}$ in the lake that would result exclusively from atmospheric deposition (i.e. in the absence of any other sources or processes). This procedure accounts for the influence of hydrology (evaporative concentration, and the effects of retention time). The ratio of the preliminary simulated $\mathrm{SO}_{4}{ }^{2-}$ concentration to observed lake concentration indicates whether the catchment is a sink (simulated:observed $>1$ ) or a source (simulated:observed $<1$ ) of $\mathrm{SO}_{4}{ }^{2-}$. Effective $\mathrm{SO}_{4}{ }^{2-}$ deposition was calculated by dividing modelled $\mathrm{SO}_{4}{ }^{2-}$ deposition by this ratio. Where effective deposition was less than model estimates, deposition was set equal to effective deposition. Where effective deposition was greater than estimated, modelled deposition remained unchanged, and a weathering source of $\mathrm{SO}_{4}{ }^{2-}$ equal to the difference between effective and modelled deposition was specified for the soil compartment.

\subsubsection{Phase two}

In the second phase of the lake calibration, ten automated calibrations were carried out for each lake using the fuzzy-fixed parameter approach, in order to match simulated and observed lake base cation concentrations. Fuzzy fixed parameters were specified as described above for soils, with lake relative area and lake retention time also being varied within uncertainty bands of $10 \%$. Soil exchangeable fractions were also used as targets in this phase of the calibration. The weathering rate optimized in this stage represents all catchment contributions of base cations to the lake, (i.e. weathering in the rooting zone and groundwater sources of base cations to the lake), and because the groundwater sources are considerable in the study catchments, this optimized rate vastly overestimates base cation weathering in the rooting zone. As such, calibration of soil $\mathrm{pH}$ (dependent on an accurate weathering rate estimate) is precluded. Accordingly, simulations of soil chemistry in the lake calibration should not be interpreted as an accurate depiction of soil response to atmospheric deposition. Rather the weathering rates calibrated during this phase are useful as estimates of the long-term base cation input (mineral weathering and groundwater) to the lake.

\subsection{Model simulations}

Each model run that reproduced all values within the target ranges under the plot and catchment scale approaches was classified as successful. Simulated and observed values were compared using model efficiency (Janssen \& Heuberger 1995) in order to evaluate model performance, with efficiencies of $100 \%$ indicating perfect agreement between simulated and target values. For all successful calibrations, one hindcast and two forecast (base case, double acid) simulations were carried out using the MAGICRUN program, and median values (for each scenario) were used to interpret catchment response to changes in atmospheric deposition over the 135 year (1900-2035) simulation period. Chemical response was evaluated using the criteria specified in the emissions management framework (soils: BS, $\mathrm{BC}: \mathrm{Al}$; lakes: $\mathrm{ANC}_{\mathrm{CB}}$ ).

\section{RESULTS AND DISCUSSION}

\subsection{Calibration}

Multiple calibrations to observed soil data were attempted for each of the 28 mineral soils using MAGICOPT. Unlike prior investigations of soil sensitivity to acid deposition in the region focussing exclusively on acid-sensitive soils, the soils included in the current study were chosen because of their location (i.e., within the study lake catchments) rather than for any identifying property. While many of the soils are acidsensitive and have low estimated weathering rate (Tab. 2 ), the range in weathering rates is much higher than previously reported (e.g. Whitfield et al. 2009). Mineralogical composition of forest soils varies considerably across these 28 sites (Fig. 4), and the proportion of weatherable (non-quartzite) minerals reaches as high as $50 \%$. These sites also exhibited a wide range in clay contents (data not shown) and CEC, while bulk density was moderately variable (Tab. 2). All sites were successfully calibrated, with the number of successful calibrations as few as four, but for most sites all 10 optimizations were successful. Targets for the four eBC fractions were reproduced at all sites, with error between simulated and observed being less than $0.01 \%$ in all cases (Fig. 5a). 


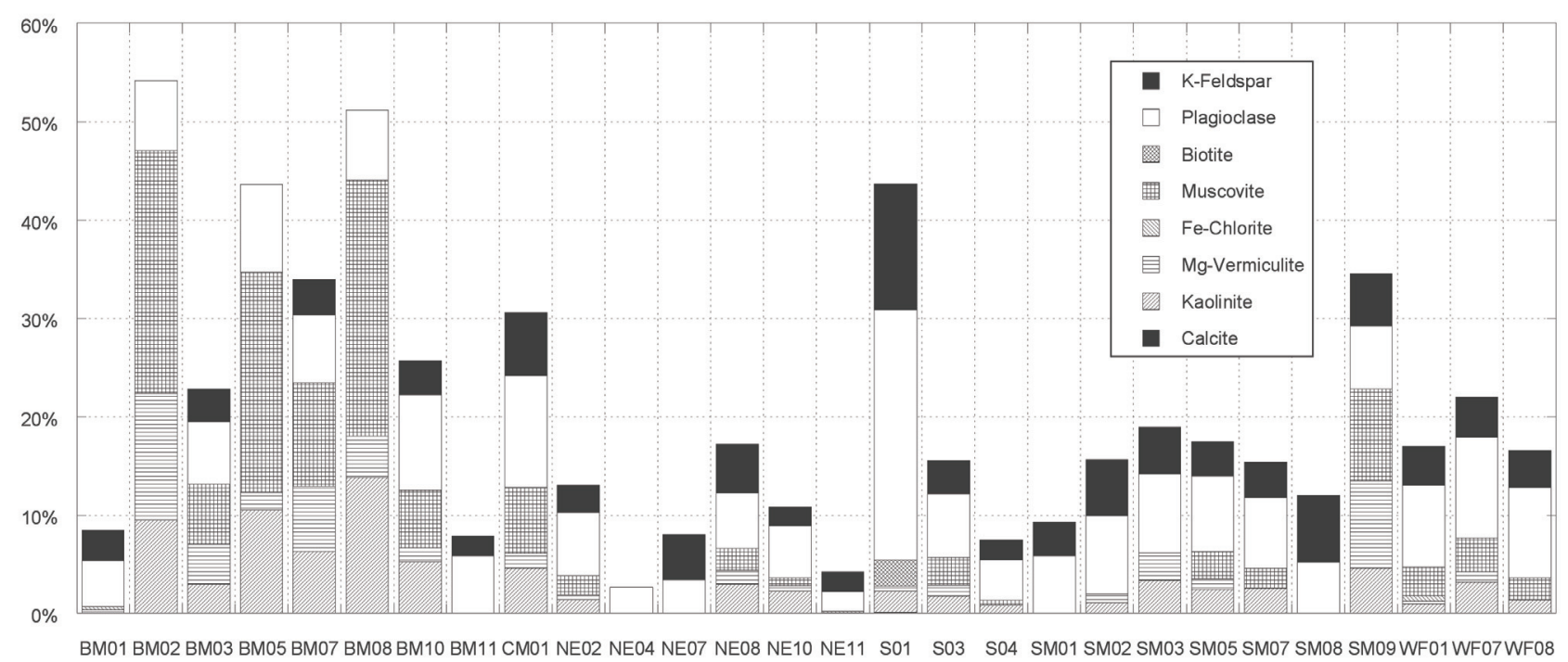

Fig. 4. Percent composition of weatherable minerals at the 28 forest plots.
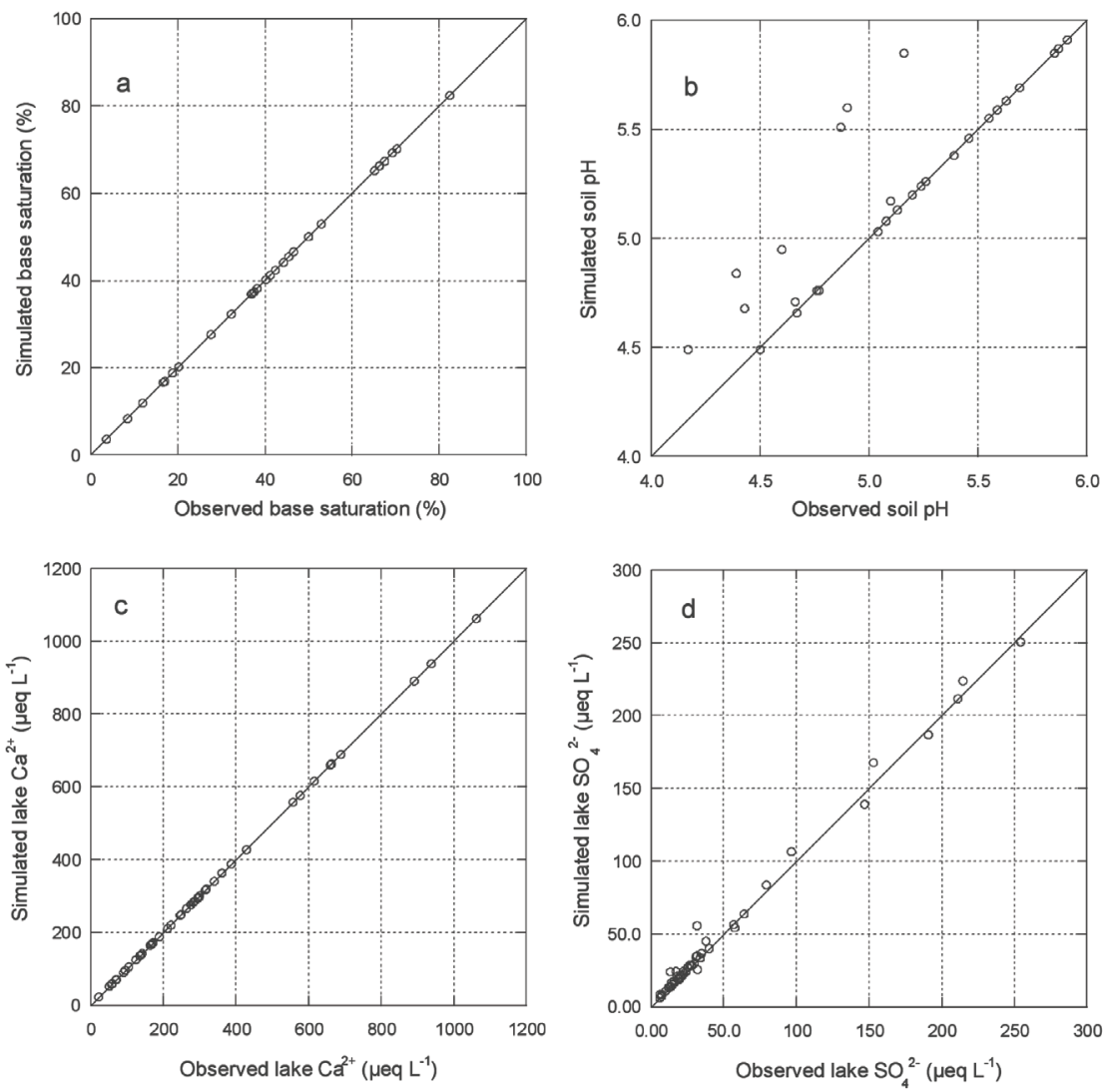

Fig. 5. Plots of model simulated and observed soil base saturation (a), soil pH (b), lake calcium $\left(\mathrm{Ca}^{2+}\right)$ concentration (c), and lake sulphate $\left(\mathrm{SO}_{4}{ }^{2-}\right)$ concentration (d) for the calibration year 2005. The 1:1 line is shown for each calibration.

The target window for a successful match of soil $\mathrm{pH}$ used here $(0.75 \mathrm{pH}$ units) was larger than previous plotscale applications for the region $(0.35 \mathrm{pH}$ units: Whitfield et al. 2009), but nonetheless observed and simulated soil $\mathrm{pH}$ were in close agreement at the majority of the sites (Fig. 5b), and model efficiency was
$71 \%$. Given that soil $\mathrm{pH}$ was approximated from laboratory measurements and not measured directly on soil solution draining from the mineral horizons, lower model efficiency for this parameter is not unexpected. For three of the sites, simulated $\mathrm{pH}$ was considerably overestimated ( $>0.5 \mathrm{pH}$ units); these sites demonstrated 
the highest estimated weathering rates, suggesting potential errors in this input parameter. Furthermore, there was a bias towards over-prediction of simulated soil $\mathrm{pH}$ among the study sites (Fig. 5b). While it has been demonstrated that PROFILE is comparable to other weathering rate estimation methods for acidsensitive soils in the AOSR (Whitfield et al. 2010b, this issue), weaker calibration performance at sites with high estimated weathering rates suggests that the model may overestimate weathering rates for less-acid sensitive soils. PROFILE weathering rate estimates are sensitive to mineral surface area used as a model input (Hodson et al. 1996), and while efforts were made to use sitespecific estimates of surface area, the weathering rate estimates stand to be improved by using measured (rather than calculated) surface area as an input parameter. A default soil moisture for the region was also used in the weathering rate calculations; use of measured soil moisture may yield improved weathering rate estimates. As PROFILE weathering rate estimates are subject to some uncertainty, caution should be used when drawing conclusions about the sites with high estimated weathering rates. Differences in land-cover between the forest soil plot and the (larger) grid used to establish the deposition fields could also result in minor errors in deposition fluxes that could influence soil $\mathrm{pH}$ calibration accuracy.

Successful calibrations to observed lake chemistry were generated for all 50 study sites. Agreement between observed and simulated surface water base cation concentrations was excellent (Fig. 5c), with model efficiency reaching $100 \%$. Model performance for lake anion concentrations was also good, ranging from $94 \%$ to $100 \%$. Nitrogen retention in the soil compartment specified during phase one of the calibration was very high for both $\mathrm{NH}_{4}{ }^{+}$(minimum: $46 \%$, median: $100 \%$ ) and $\mathrm{NO}_{3}^{-}$(minimum: 88\%, median: 100\%). Model efficiency was marginally lower for some of the parameters $\left(\mathrm{NH}_{4}^{+}, \mathrm{NO}_{3}{ }^{-}, \mathrm{Cl}^{-}, \mathrm{SO}_{4}{ }^{2-}\right)$ calibrated in phase one because all parameters were fixed in phase one, while in phase two a number of parameters (lake relative area, discharge) were varied within their specified uncertainty bands $( \pm 10 \%)$. For catchments where the optimization yields a set of calibrations that systematically shift away from the fixed value, some error will result. Nonetheless, this approach to calibration yielded good agreement between simulated and observed ion concentrations (model efficiencies of $99 \%, 96 \%$ and $94 \%$ for $\mathrm{SO}_{4}{ }^{2-}, \mathrm{NH}_{4}^{+}$and $\mathrm{NO}_{3}^{-}$, respectively) (Fig. 5d). Calibrations to lake chemistry required generous limits on weathering rates, and calibrations were equally successful for sites with site-specific and sub-region average soil data. Comparison of the soil profile (rooting zone) base cation weathering rate estimate and a MAGIC calibrated catchment base cation source estimate at the 28 sites where soil data were available indicates that the catchment-based estimate was systemati- cally higher (24 of 28 sites), while for those sites where PROFILE estimated weathering rate was high, the two sources are comparable (Fig. 6).

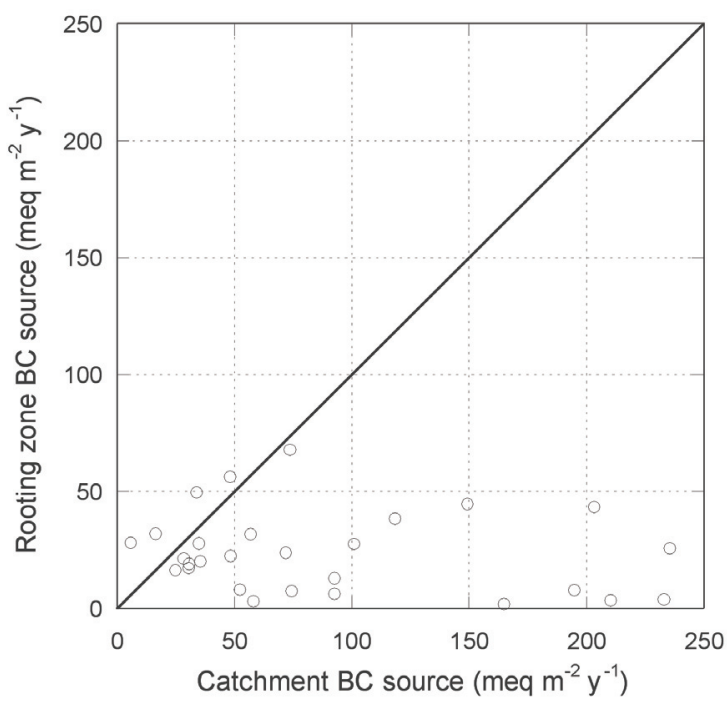

Fig. 6. Comparison of PROFILE estimated mineral soil (rooting zone) weathering rates and MAGIC calibrated base cation (BC) inputs to the lake for the 28 sites where both plotscale and catchment calibrations were completed.

\subsection{Soil chemical response}

Model simulations over the 105 year hindcast period indicate that there has been limited change in BS at the 28 forest plots, but BS values vary considerably across the sites. In other acid-sensitive regions of Canada, model reconstructions of soil chemistry have shown BS decreases that coincide with periods of peak $\mathrm{SO}_{4}{ }^{2-}$ deposition (Aherne et al. 2003; Whitfield et al. 2007). This suggests that to date $\mathrm{SO}_{4}{ }^{2-}$ deposition levels (Tab. 1 ) in the AOSR have resulted in only limited removal of base cations from the soil exchange complex as a buffer of mobile $\mathrm{SO}_{4}{ }^{2-}$ in soil waters. At present, $\mathrm{S}$ deposition across much of the AOSR remains low relative to other polluted regions of eastern North America where the density of $\mathrm{SO}_{2}$ sources is high and contributes to a much higher $\mathrm{SO}_{4}{ }^{2-}$ deposition level (Jeffries et al. 2003). Further, hindcast base cation deposition scenarios (Whitfield et al. 2010a, this issue) suggest that deposition has increased from the pre-industrialization level, which has likely offset some of the increase in $\mathrm{SO}_{4}{ }^{2-}$ deposition in the AOSR region. Across the southern sub-regions base cation deposition averages approximately $70-80 \%$ of $\mathrm{SO}_{4}{ }^{2-}$ deposition on an equivalent basis, while at the northern sites base cation deposition is approximately equal to $\mathrm{SO}_{4}{ }^{2-}$ deposition. Evidently, little change in soil chemistry should be expected under the base case forecast scenario. Under elevated acid deposition (double acid scenario) only marginal decreases $($ mean $=0.1 \%)$ in base saturation are predicted within the simulated timeframe (30 years); how- 
ever where critical loads are exceeded, continued decreases in BS can be expected over the long-term.

Simulated changes in molar BC:Al were highly variable, and were dependent on weathering rate. At some sites, modelled change from pre-industrial condition was considerable. Comparison of model simulations with the threshold of tolerable change specified under the EMF suggests that many sites could reach a state of violation under both the base case and double acid deposition scenarios; however with few exceptions, the modelled $2005 \mathrm{BC}: \mathrm{Al}$ ratio is much higher than the critical $\mathrm{Bc}: \mathrm{Al}$ of 10 (where $\mathrm{Bc}=\mathrm{Ca}^{2+}, \mathrm{Mg}^{2+}$ and $\mathrm{K}^{+}$) typically used as the threshold for damage in eastern Canada (Ouimet et al. 2006) and the BC:Al of 2 used as a threshold in Alberta, suggesting limited impact. It must be cautioned that model simulated values of $\mathrm{BC}: \mathrm{Al}$ are dependent on the KAl value used during model calibration, and few data are available for this parameter; improved understanding of aluminium behaviour in these soils would be beneficial for predictions of molar $\mathrm{BC}: \mathrm{Al}$ in soil solution. The sites with low weathering rates are likely to have a low $\mathrm{BC}: \mathrm{Al}$, and may be at greater risk of impact to acid-sensitive biota. Research linking changes in soil chemistry to health of the vegetation in this region is necessary for identifying the areas at greatest risk. Further, while harvesting was not included as a stressor in this application, removal of wood from these sites where weathering rates are low may deplete the soil pool of base cations, and may accelerate soil acidification. Investigations of forest sustainability are necessary if harvesting practices are carried out in these regions with low weathering rates.

\subsection{Lake chemical response}

A higher critical $\mathrm{ANC}_{\mathrm{CB}}$ limit $\left(75 \mu \mathrm{eq} \mathrm{L}^{-1}\right)$ than used elsewhere in Canada ( $40 \mu \mathrm{eq} \mathrm{L}{ }^{-1}$ : Henriksen et al. 2002) was chosen for protection of lakes in the region, owing to the strong influence of organic acids. In humic lakes, where dissolved organic acid concentrations are high, weak acids with low $(<3.5)$ pK values will be deprotonated and can act similarly to strong acids $\left(\mathrm{SO}_{4}{ }^{2-}, \mathrm{NO}_{3}{ }^{-}, \mathrm{Cl}^{-}\right)$, effectively depressing ANC. In the study lakes, DOC concentrations are consistently high (minimum $=9.0 \mathrm{mg} \mathrm{L}^{-1}$ ), but exhibit considerable variability (Tab. 1), and as such will have a range in influence on ANC. Lydersen et al. (2004) established a method for modifying the critical ANC limit to account for the portion of organic acids that have low $(<3.5) \mathrm{pK}$ values (i.e. act as strong acids), such that a lake-specific ANC limit could by applied. Correcting $\mathrm{ANC}_{\mathrm{CB}}$ across the 50 study lakes using this technique would result in an average decrease of $79 \mu \mathrm{eq} \mathrm{L}^{-1}$, and given that $\mathrm{ANC}_{\mathrm{CB}}$ is quite high at the majority of study lakes (Fig. 7a), few are close to the critical limits used for eastern Canada even after correcting for organic acid influence.
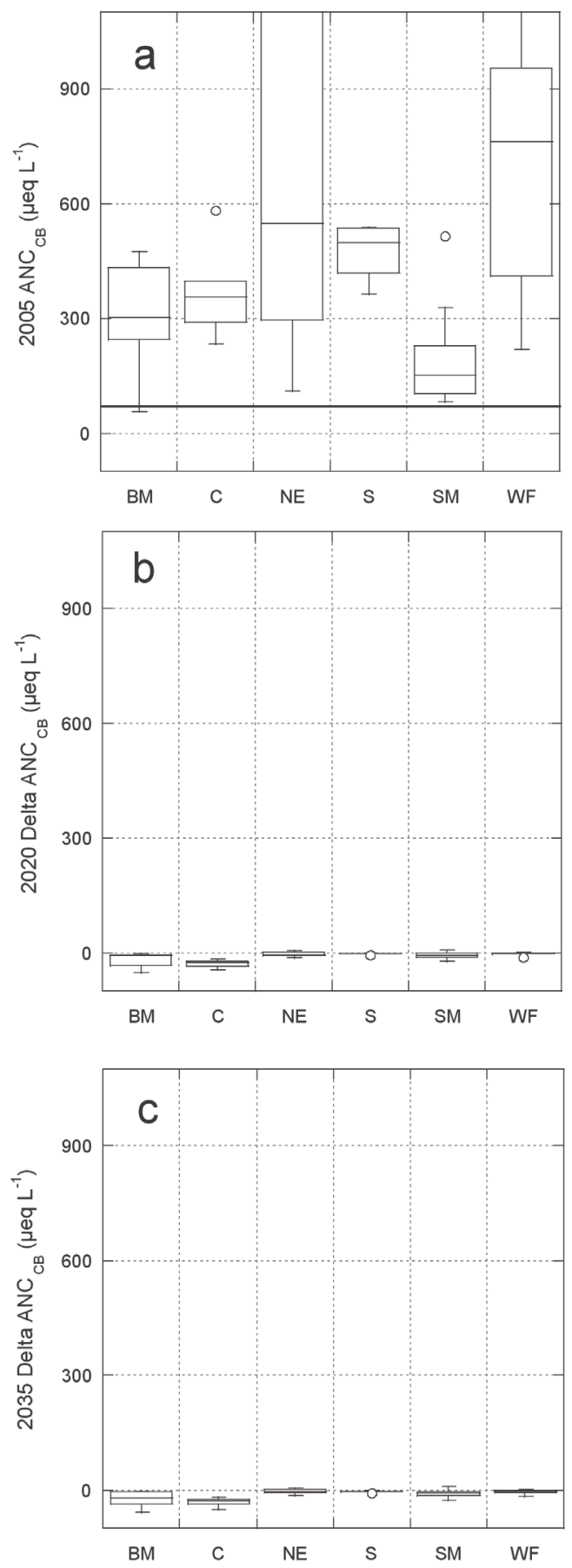

Fig. 7. Observed charge balance acid neutralizing capacity $\left(\mathrm{ANC}_{\mathrm{CB}}\right)$ in 2005 (a) with critical threshold indicated by black horizontal line, and simulated change in $\mathrm{ANC}_{\mathrm{CB}}$ through to 2020 (b) and 2035 (c) under the double acid scenario. The boxplot shows the median, upper and lower quartiles and outliers are indicated by an open circle for each of the six subregions in the study area: Birch Mountains (BM), Caribou Mountains (C), Northeast of Fort McMurray (NE), Shield (S), Stony Mountains (SM) and West of Fort McMurray (WF). 
Average $\mathrm{ANC}_{\mathrm{CB}}$ during the monitoring period ranged across the study lakes $\left(57-1762 \mu \mathrm{eq} \mathrm{L^{-1 }}\right.$ ), indicating considerable variability in acid-sensitivity (Fig. 7a). Simulated $\mathrm{ANC}_{\mathrm{CB}}$ changed little during the hindcast period, with most lakes showing only marginal decreases (average change $=-2.6 \%$ ); one lake was estimated to have an $\mathrm{ANC}_{\mathrm{CB}}$ below the critical threshold, but the estimated historical condition is also below the threshold, indicating that it has not been exceeded as a result of acid deposition. Given that catchment sources of base cations are considerable for most lakes (Fig. 6) and that most of the study catchments are net sinks for atmospherically deposited $\mathrm{SO}_{4}{ }^{2-}$, presumably due to substantial $\mathrm{S}$ storage in peatlands, a tempered response to changes in atmospheric deposition levels is not unexpected. This is particularly true for the two northern sub-regions where $\mathrm{SO}_{4}{ }^{2-}$ deposition levels are considerably lower than at the other sites.

Forecast scenarios under base case deposition suggest that negligible change in $\mathrm{ANC}_{\mathrm{CB}}$ will take place within the 30 year period of interest for the EMF (average change $=0.9 \%$ ). Small increases in $\mathrm{ANC}_{\mathrm{CB}}$ may take place over the short term under base case deposition levels, owing to low effective $\mathrm{SO}_{4}{ }^{2-}$ deposition at many catchments and sustained base cation deposition at elevated deposition levels. Forecast simulations predict that small relative decreases in $\mathrm{ANC}_{\mathrm{CB}}$ will occur at the study catchments in the event that deposition of $\mathrm{S}$ and $\mathrm{N}$ increases to a level twice that of 2005 deposition (Fig. 7b, c). Few lakes have ANC in the range of the critical threshold (2005 median $\mathrm{ANC}_{\mathrm{CB}}: 359 \mu \mathrm{eq} \mathrm{L} \mathrm{L}^{-1}$ ), and consequently the impacts from acidification are expected to be very limited. Only one lake (SM08) is projected to be depressed below the critical threshold $\mathrm{ANC}_{\mathrm{CB}}$ of $75 \mu \mathrm{eq} \mathrm{L} \mathrm{L}^{-1}$ under this forecast scenario and consequently acidification patterns within the timeframe of interest for the EMF are unlikely to stimulate an action to introduce emissions controls.

With the exception of some of the BM catchments, rooting zone weathering rate estimates are generally low to moderate (Tab. 2) and a comparison of rooting zone weathering rates (estimated with PROFILE) and catchment-based base cation sources (derived through calibration to lake chemistry) provides clear evidence that there are large contributions of base cations to the lakes that can not be accounted for by weathering processes in the upper regions of the mineral soil deposits (Fig. 6). Passage of water through mineral rich geologic deposits and subsequent upwelling in lakes or peatlands is likely. Comparison of rooting zone and catchment-based weathering rates at the 28 catchments where plot-scale analysis was performed indicates that rooting zone contributions make up less than $30 \%$ of the base cation flux to the lakes at $50 \%$ of the catchments. At the SM catchments, rooting zone weathering contributions are very low, but tended to represent a somewhat greater proportion of the base cation sources in the catchments.
Groundwater base cation fluxes to the lakes may be more limited in this sub-region (e.g. Whitfield et al. 2010a, this issue), consequently these catchments are among the most acid-sensitive.

\subsection{Limitations}

Perhaps the biggest challenge to model application in the study region is the hydrology, and assessing connectivity between mineral uplands and lake basins on this landscape is difficult. Base cation sources to the lakes far outweigh contributions from weathering in the rooting zone, and using a traditional (catchment) regional MAGIC application as has been previously used in Canada (e.g., Aherne et al. 2003; Whitfield et al. 2007) can not provide adequate representation of forest soil response to acidifying deposition in the study region. Calibrated catchment weathering rates would overestimate weathering in the rooting zone of mineral soils and underestimate sensitivity to acid-deposition. The lumped parameter application of MAGIC in the AOSR presented here addresses this challenge by using a dual (plot-scale and lumped catchment) application to generate hindcast and forecast simulations of soil and surface water chemistry across the region. This method provides a means of assessing catchment response to changes in atmospheric deposition, but in order to holistically evaluate the response of the terrestrial catchment more comprehensive data that adequately represent the upland soils of the catchment are required in place of the single plot characterization used in the current study.

At present, data availability in the region is limited both spatially and temporally. In this assessment single soil pits within some of the study catchments were used to estimate soil chemical response to changing atmospheric deposition level. Given the large catchment areas, the inherent spatial variability in soil properties, and the contrast in soil sensitivity to acid deposition exhibited within some of the sub-regions, there is a strong need for additional soil data in order to be able to provide a quantitative estimate of the spatial response of forest soils across the AOSR as required for the EMF. The use of multiple soil pits for individual sites would also aid in reducing the uncertainty around predictions generated with the plot-scale approach. In addition, uncertainty surrounding model simulations of lake chemistry may result from limited data being available for calibration. For the lake application, long-term average lake chemistry for August/September was used as a target. Strong evaporative enrichment of surface waters during the summer months has been documented in the region and calibrating to this time point could result in overestimation of the ion contributions to, and export from, the lakes. Furthermore, the temporal data record used for calibration is limited to only a few years, and it has been shown that uncertainties in model simulations are lower when calibrations incorporate a longer time 
series (Larssen et al. 2005). Nevertheless, the regional lake response to changes in acid deposition was coherent and model simulations suggest very limited change in surface water chemistry, thus there is reasonable confidence that impacts of acidification on lakes in the AOSR will be limited.

Runoff from these catchments is difficult to assess, as channelized runoff is rare, and catchment boundaries are subject to considerable uncertainty. The accuracy of runoff estimates generated using an isotopic mass balance (e.g., Gibson et al. 2002) relies heavily on the validity of the catchment boundaries used. For catchments where isotope mass balance runoff estimates were low $(<0.1 \mathrm{~m})$, model calibration was generally not possible, suggesting an overestimation of runoff area. The use of interpolated runoff allowed for model calibration to lake chemistry, although for some sites with low runoff the frequency of successful calibration was low. In the catchment-based application, discharge was included as a fuzzy-fixed parameter as a means of accounting for some of this uncertainty. Evidently, future model applications for the region stand to benefit from improved data detailing runoff contributing terrain within the catchments.

The accuracy of future simulations may be impaired by a number of processes. In some catchments, large collapse scars evidence permafrost melt and in these catchments discharge can exceed precipitation (J.J. Gibson, pers. comm.). This did not preclude model calibration in the current study, but future hydrologic patterns will vary on a catchment-specific basis, depending on the extent and duration of permafrost melt. The accuracy of future model projections may be compromised by the ongoing permafrost melt in the region and future lake ion concentrations could be dramatically influenced by this process. Simulation of future $\mathrm{SO}_{4}{ }^{2-}$ concentrations may be impaired by the somewhat coarse calibration used for the regional application, or by potential (climate driven) changes in $\mathrm{S}$ cycling in the catchments that result in release of $\mathrm{SO}_{4}{ }^{2-}$ from peatland stores (see Whitfield et al. 2010a, this issue). Nitrogen dynamics are also subject to uncertainty; however deposition levels remain much lower than in areas where evidence of $\mathrm{NO}_{3}{ }^{-}$leaching has been documented in Canada (Jeffries 1995). In view of projected $N$ deposition levels, the risk of $\mathrm{N}$ saturation is low, and because the majority of lakes have high $\mathrm{ANC}_{\mathrm{CB}}, \mathrm{N}$ deposition is not high enough to cause widespread acidification (depression of $\mathrm{ANC}_{\mathrm{CB}}$ to the critical threshold).

\section{CONCLUSIONS}

A dual calibration approach to model application is required in the AOSR in order to simulate the response of both forest soils and lakes to changes in atmospheric deposition. The model simulations presented here for 28 forest plots and 50 lake catchments suggest that lake and soil chemistry have shown limited response to changes in acid deposition across the AOSR. While a future increase in atmospheric acid deposition is likely to coincide with expanding oil sands production, this is unlikely to invoke acidification of acid-sensitive ecosystems in the AOSR. Nonetheless, the critical thresholds of tolerable change are stringent, and if acid deposition rises according to the double acid scenario, changes in $\mathrm{BC}$ :Al may be sufficient for emission controls as outlined by the EMF to be considered. Forest soils are the most sensitive ecosystem endpoint owing to very low weathering rates and additional data are required in order to provide a comprehensive evaluation of soil chemical response to acid deposition in the region. The vast majority of lakes are at low risk of acidification. This approach or a variant thereof could be expanded to fulfill the mandate of the EMF such that the landscape response to acid deposition within the region is represented more completely.

\section{ACKNOWLEDGEMENTS}

Financial support for this work was provided through a Collaborative Research and Development Grant from the Natural Sciences and Engineering Research Council (NSERC) and the Cumulative Environmental Management Association (CEMA) awarded to JA and SAW, and an NSERC scholarship awarded to CJW. This research was undertaken, in part, thanks to funding from the Canada Research Chairs Program and an NSERC Discovery grant. Provision of data by P. McEachern and R. Hazewinkle at Alberta Environment was instrumental to the completion of this work. The authors wish to thank J.J. Gibson for many valuable discussions and for providing IMB runoff estimates and catchment area data, and M. Posch for providing interpolated runoff estimates. R.K. Wieder's provision of IER column data is also greatly appreciated. A. Adkinson, D. Laxton, M. McDonald, B. Parsons, and T. Seabert's assistance with sample collection is appreciated. Many thanks also to H. Broadbent for her support and assistance with laboratory analyses.

\section{REFERENCES}

Aherne, J., P.J. Dillon \& B.J. Cosby. 2003. Acidification and recovery of aquatic ecosystems in south central Ontario, Canada: regional application of the MAGIC model. Hydrol. Earth Syst. Sci., 7: 561-573.

Aherne, J., M. Posch, M. Forsius, J. Vuorenmaa, P. Tamminen, M. Holmberg \& M. Johansson. 2008. Modelling the hydro-geochemistry of acid-sensitive catchments in Finland under atmospheric deposition and biomass harvesting scenarios. Biogeochem., 88: 233-256.

Bennett, K.E., J.J. Gibson \& P.M. McEachern. 2008. Wateryield estimates for critical loadings assessment: comparisons of gauging methods versus an isotopic approach. Can. J. Fish. Aquat. Sci., 65: 83-99.

Carou, S., I. Dennis, J. Aherne, R. Ouimet, P.A. Arp, S.A. Watmough, I. Demerchant, M. Shaw, R. Vet, V. Bouchet \& M. Moran. 2008. A national picture of acid deposition critical loads for forest soils in Canada. Canadian Council of Ministers of the Environment, PN 1412.

Cosby, B.J., G.M. Hornberger, J.N. Galloway \& R.F. Wright. 1985. Modeling the effects of acid deposition: assessment 
of a lumped parameter model of soil water and streamwater chemistry. Water Resour. Res., 21: 51-63.

Cosby, B.J., R.C. Ferrier, A. Jenkins \& R.F. Wright. 2001. Modelling the effects of acid deposition: refinements, adjustments and inclusion of nitrogen dynamics in the MAGIC model. Hydrol. Earth Syst. Sci., 5: 499-517.

Devito, K.J., I.F. Creed, R.L. Rothwell \& E.E. Prepas. 2000. Landscape controls on phosphorous loading to boreal lakes: implications for the potential impacts of forest harvesting. Can. J. Fish. Aquat. Sci., 57: 1977-1984.

De Vos, B., M. Van Meirvenne, P. Quataert, J. Deckers \& B. Muys. 2005. Predictive quality of pedotransfer functions for estimating bulk density of forest soils. Soil Sci. Soc. Am. J., 69: 500-510.

Dillon, P.J., D.S. Jeffries, W. Snyder, R. Reid, N.D. Yan, D. Evans, J. Moss \& W.A. Scheider. 1978. Acidic precipitation in south-central Ontario: recent observations. J. Fish. Res. Board Can., 35: 809-815.

Environment Canada. 2009. National climate data and information archive. Available at: climate.weatheroffice. ec.gc.ca/climateData/canada_e.html (verified January 28, 2009), Meteorological Service of Canada, Environment Canada, Downsview, ON.

Gibson, J.J., E.E. Prepas \& P.M. McEachern. 2002. Quantitative comparison of lake throughflow, residency, and catchment runoff using stable isotopes: modelling and results from a regional survey of boreal lakes. J. Hydrol., 262: $128-144$.

Gorham, E. 1998. Acid deposition and its ecological effects: a brief history of research. Environ. Sci. Pol., 1: 153-166.

Henriksen, A., P.J. Dillon \& J. Aherne. 2002. Critical loads of acidity for surface waters in south-central Ontario, Canada: regional application of the Steady-State Water Chemistry (SSWC) model. Can. J. Fish. Aquat. Sci., 59: 1287-1295.

Hodson, M. E., S.J. Langan \& J. Wilson. 1996. A sensitivity analysis of the PROFILE model in relation to the calculation of soil weathering rates. Appl. Geochem., 11: 835-844.

Hodson, M.E., S.J. Langan \& S. Meriau. 1998. Determination of mineral surface area in relation to the calculation of weathering rates. Geoderma, 83: 35-54.

Janssen, P.H.M. \& P.S.C. Heuberger. 1995. Calibration of process-oriented models. Ecol. Modell., 83: 55-66.

Jeffries, D.S. 1995. A preliminary assessment of nitrogenbased fresh water acidification in southeastern Canada. Water Air Soil Pollut., 85: 433-438.

Jeffries, D.S., T.A. Clair, S. Couture, P.J. Dillon, J. Dupont, W. Keller, D.K. McNicol, M.A. Turner, R. Vet \& R. Weeber. 2003. Assessing the recovery of lakes in southeastern Canada from the effects of acidic deposition. Ambio, 32: 176-182.

Kuylenstierna, J., H. Rodhe, S. Cinderby \& K. Hicks. 2001. Acidification in developing countries: Ecosystem sensitivity and the critical load approach on a global scale. Ambio, 30: 20-28.

Larssen, T. \& G.R. Carmichael. 2000 Acid rain and acidification in China: the importance of base cation deposition. Environ. Pollut., 110, 89-102.

Larssen, T., T. Hogasen \& B.J. Cosby. 2005. Impact of time series data on calibration and prediction uncertainty for a deterministic hydrogeochemical model. Ecol. Modell., 207: 22-33.

Lydersen, E., T. Larssen \& E. Fjeld. 2004. The influence of total organic carbon (TOC) on the relationship between acid neutralizing capacity (ANC) and fish status of Norwegian lakes. Sci. Tot. Environ., 326: 63-69.

Mesinger, F., G. DiMego, E. Kalnay, K. Mitchell, P. C. Shafran, W. Ebisuzaki, D. Jovic, J. Woollen, E. Rogers, E. H. Berbery, M. B. Ek, Y. Fan, R. Grumbine, W. Higgins, H. Li, Y. Lin, G. Manikin, D. Parrish \& W. Shi. 2006. North American Regional Reanalysis: A long-term, consistent, high-resolution climate dataset for the North American domain, as a major improvement upon the earlier global reanalysis datasets in both resolution and accuracy. Bull. Amer. Meteorol. Soc., 87: 343-360.

Ouimet, R., P.A. Arp, S.A. Watmough, J. Aherne \& I. Demerchent. 2006. Determining and mapping critical loads of acidity and exceedances for upland forest soils in eastern Canada. Water Air Soil Pollut., 172: 57-66.

Overrein, L.N., H.M. Seip \& A. Tollan. 1981. Acid precipitation-effects on forest and fish. Final Report of the SNSFproject, 1972-1980, SNSF-FR 19/80.

Rogora, M., A. Marchetto \& R. Mosello. 2003. Modelling the effects of atmospheric sulphur and nitrogen deposition on selected lakes and streams of the Central Alps (Italy). Hydrol. Earth Syst. Sci., 7: 540-551.

Sefton, C.E.M. \& A. Jenkins. 1998. A regional application of the MAGIC model in Wales: calibration and assessment of future recovery using a Monte-Carlo approach. Hydrol. Earth Syst. Sci., 2:521-531.

Schöpp, W., M. Posch, S. Mylona \& M. Johannson. 2003. Long-term development of acid deposition (1880-2030) in sensitive freshwater regions in Europe. Hydrol. Earth Syst. Sci., 7: 436-446.

Stoddard, J.L., D.S. Jeffries, A. Lukewille, T.A. Clair, P.J. Dillon, C.T. Driscoll., M. Forsius, M. Johannessen, J.S. Kahl, J.H. Kellogg, A. Rebsdorf, B.L. Skjelkvale, M.P. Stainton, T. Traaen, H. van Dam, K.E. Webster, J. Wieting \& A. Wilander. 1999. Regional trends in aquatic recovery from acidification in North America and Europe. Nature, 401: 575-578.

Timilsina, G.R., N. LeBlanc \& T. Walden. 2005. Economic impacts of Alberta's Oil Sands. Canadian Energy Research Institute, Calgary, AB. Available at: www.ceri.ca/Publications/documents/OilSandsReport-Final.PDF

Vet, R.J. \& M. Shaw. 2004. 1994-1998 average dry deposition velocities calculated using the MSC Air Quality Research Branch dry deposition model (RDM). Meteorological Service of Canada, Environment Canada, Toronto, Ontario.

Vogt, R.D., H.M. Seip, T. Larssen, D. Zhao, R. Xiang, J. Xiao, J. Luo \& Y. Zhao. 2006. Potential acidifying capacity of deposition: experiences from regions with high $\mathrm{NH}_{4}{ }^{+}$and dry deposition in China. Sci. Tot. Environ., 367: 394-404.

Warfvinge, P. \& H. Sverdrup. 1992. Calculating critical loads of acid deposition with PROFILE - A steady-state soil chemistry model. Water Air Soil Pollut., 63: 119-143.

Whitfield, C.J. 2009. A dynamic modelling assessment of soil and lake chemical response to elevated $S$ and $N$ deposition in the Athabasca Oil Sands Region. PhD Dissertation, Trent University, Peterborough, ON.

Whitfield, C.J., J. Aherne \& S.A. Watmough. 2009. Modelling soil acidification in the Athabasca Oil Sands Region, Alberta, Canada. Environ. Sci. Technol., 43: 5844-5850.

Whitfield, C.J., J. Aherne, P.D. Dillon \& S.A. Watmough. 2007. Modelling acidification, recovery and target loads for headwater catchments in Nova Scotia, Canada. Hydrol. Earth Syst. Sci., 11: 951-963.

Whitfield, C.J., J. Aherne, B.J. Cosby \& S.A. Watmough. 2010a. Modelling boreal lake catchment response to anthropogenic acid deposition. J. Limnol., 69(Suppl. 1): 135146. DOI: 10.3274/JL10-69-S1-14.

Whitfield, C.J., J. Aherne, S.A. Watmough \& M. McDonald. 2010 b. Estimating the sensitivity of forest soils to acid deposition in the Athabasca Oil Sands Region, Alberta. J. Limnol., 69(Suppl. 1): 201-208. DOI: 10.3274/JL10-69S1-20.

Wright, R.F., T. Larssen, L. Camarero, B.J. Cosby, R.C. Ferrier, R.C. Helliwell, M. Forsius, A. Jenkins, J. Kopacek, V. Majer, F. Moldan, M. Posch, M. Rogora \& W. Schöpp. 2005. Recovery of acidified European surface waters. Environ. Sci. Technol., 39: 64A-72A 